\title{
Editorial: toward getting some facts less snarled?
}

\section{Caroline Allison and Reginald Green}

On a cloth untrue,

With a twisted cue

And elliptical billiard balls.

- Gilbert and Sullivan

Mistakes are mistakes.

$$
\text { - J. K. Nyerere }
$$

Do not go silent

Into that good night,

But rage, rage

Against the dying of the light.

- Dylan Thomas

\section{9-1985: Confidence Through Concern to Crisis}

IDS has been involved in study, research, teaching and advising on sub-Saharan African development since its inception over two decades ago. Some IDS Fellows' experience in Africa goes back a quarter of a century. In the late 1970s most IDS members working in Africa were optimistic. Problems, mistakes and areas of uncertainty were clear, but the general impression was one of growing knowledge, more and - perhaps more equitable development. SSA as a whole had apparently weathered the 1973-75 global economic shocks fairly speedily and appeared (as GDP figures later confirmed) to be doing better over 1976-79 than in any previous four-year period. Some countries were exceptions, and in 1979-80 IDS membes tended to see the signs of an overall reversal of trend in the context of specific countries. Growing doubts were increased in the autumn of 1981 by the appearance of the World Bank's Accelerated Development Report.

\section{1-1985: The New Conventional Wisdom}

The Accelerated Development Report did not represent a totally new analysis of SSA nor a new academic perspective on public economic policy. Its chief author, Eliot Berg, had been writing similar - indeed clearer and more purist - analytical and policy prescriptions for two decades. The very different OECD (and especially US and UK) response to the 1979 as opposed to the 1974 international economic crises already symbolised a change towards the emergence of a less cautious, more radical, more market and less public sector/state intervention oriented mood on public policy generally. What then was the significance of Accelerated Development?

First, it marked the first widely read and seriously studied application of the 'new conventional wisdom' to Africa. Second, it came at a time when the world climate of policy and - less uniformly - analytical opinion was already shifting in the directions it advocated. Third, by 1981 a majority of SSA economies (whatever their 1976-79 records) were enmeshed in a very serious economic malaise which neither holding operations nor 'more of the same' seemed likely to overcome. Governments, aid agencies and analysts were faute de mieux in the market for something new. Fourth, Accelerated Development had the reputation, influence and financial clout of the World Bank behind it, a doubly telling point since it appeared to be a recantation of key elements (including modernisation, large-scale, high technology and 'elimination of mass poverty'/'basic needs') at the core of the Bank's previous thinking, strategic and policy advice, and funding on SSA. Fifth, any serious analyst or reflective decision-taker could easily identify policy errors made by - or on behalf of - most SSA countries, especially in implementation and total unprojected results. These suggested either faulty analytical tools, imperfect data and/or the failure to relate analysis to context. The Report appeared to meld a number of random empirical snapshots into evidence on broader analytical and strategic issues. To a degree it achieved this, although at the expense of blurring contextual issues and diversity still further.

The dialogue touched off by the World Bank Report has clearly been necessary and in many respects positive: 
- the production and distribution record (whether in terms of incentive or equity efficiency) in almost all SSA countries since 1979 has been totally unsatisfactory and the type of adjustment that worked for a majority over 1974-75 has usually failed utterly. New contexts require new policies, which, in turn, require new analytical emphases and approaches.

- the importance of real incentives - and in particular of real prices (especially real grower prices both official and effective, real wages and real foreign exchange prices) - as well as monetary and price considerations more generally had been underexamined by much structuralist analysis. At the policy level, while SSA governments placed very heavy stress on prices as policy tools (probably more than in any other region), they did so inconsistently, on the basis of imperfect data, with major gaps. In addition nominal and real prices were frequently confused.

- with falling real resource availability, public sector programmes, public enterprises and efforts to redistribute consumption, in particular, needed to be re-analysed. To attempt to cut back while doing everything much as before was clearly likely to be an inefficient 'solution' by any test. Similarly the clash between the analysts' (and the aid agencies') concept of a benign, well informed. civil and participatory, administratively competent and national interest oriented (in the Keynesian sense) state in many SSA countries raised serious questions as to analytical relevance.

- the stress placed by many SSA governments and almost all external sources of finance on largescale, modern, capital-import-energy intensive approaches in all sectors (not least agriculture) had already been questioned by many structuralist and basic needs oriented analysts. With changes in relative world prices from 1973 and declines in SSA's earned import capacity, this strategy increasingly looked to be inefficient on market criteria, and impossible in structuralist or general macroeconomic terms.

- few SSA states, including the large minority which had actively promoted exports and were seen as committed to export led growth, had coherent external balance projections and still less articulated ways to adjust to these. Nor did they have coherent strategies and the means to implement them at sectoral and product level, whether by price incentives, investment or other means.

- overall agricultural output in SSA has been growing less rapidly than population for a quarter of a century. Since 1979, with very few exceptions whatever strategy, investment and policy packages have been applied, the decline has accelerated, suggesting a need to rethink all applied and most analytical approaches. Certainly natural disasters and a clear secular fall in rainfall from the mid-1960s contributed. Increasing inability (by public and private sectors) to deliver inputs, basic services, incentive goods, market outlets and prices to sustain or restructure production to avert the worsening human impact of drought have, however, been major factors in this process of negative development. The decline has descended to the point at which 1985 sees 30 million people in real danger of starvation with no clear analytic, strategic or programmatic basis yet in sight for projecting any early reversal.

\section{- And Its Adjustment}

The dialogue has resulted in significant reappraisal of some of the "new conventional wisdom's' initial tenets. That is to be expected: new formulations always have rough edges. A near universal result of functional dialogue is partial synthesis, even if this is sometimes only skin deep.

First, it is now increasingly agreed that unselective expansion of primary exports is unlikely to lead to rapid recovery (see Martin Godfrey in this issue) and that, except in special cases, e.g. Botswana, self sufficiency in basic food is likely to be efficient in output, distribution and risk reduction terms. These points, the first a reversal and the second a clarification of Accelerated Development, are apparent in the Joint Programme of Action [World Bank 1984].

Second, Accelerated Development's anti-import substitution thrust has been modified towards a more analytically consistent position. Efficient import substitution in food, energy, agricultural inputs, and (less uniformly) 'incentive', i.e. basic consumer goods, has now been added as the counterpart of efficient export promotion in the 'new conventional wisdom' (an area to which Manfred Bienefeld's article on industry is relevant).

Third, having established the importance of price, the mainst ream with in the 'new conventional wisdom' has become much readier to accept that, however necessary, getting the prices right requires parallel sectoral and micro policies on the physical side if it is to make lasting changes on real relative prices or output. Michael Lipton's articlc argues this in respect to agricultural research and its relationship to agricultural policy success. Equally the costs, even in 
narrow economic terms, of radical adjustments to relative prices, especially in a context of overall falls in real resources per capita, are seen as high, i.e. price instruments are not cheap and easy to use. Of ten these are so high, as to render them unusable or unsustainable without supporting injections of real resources to cover the period before output can respond.

Fourth, while clearly still of the view that in general public enterprises are less efficient than private and that state services and policy were overextended, there has been a shift toward noting diversity of experience; accepting that wholesale privatisation poses its own problems, not least in rural health and education; and seeking to achieve tighter priorities and more efficient use of available resources within the public sector rather than dismantling it wholesale. ${ }^{1}$

Fifth, at least some contributions (e.g. by the World Bank) to the 'new conventional wisdom' have recently reaffirmed that the economic malaise in sub-Saharan Africa should be seen primarily as a human tragedy and that the limitations of price centred policies have particularly serious negative implications for the absolutely poor. This is especially true for the poorest peasan ts who produce primarily food and housing for their own use. Major constraints to their short or long term productivity are posed by lack of access to basic education, health and pure water facilities. The general attack on redistribution has been refocused to advocate, if not yet articulate, more cost efficient approaches to achieving universal access to basic services (seen as production efficient) and to devising ways of increasing output relevant to the peasant household head, whose immediate challenge is to produce enough for his or her family to eat.

\section{Internal Versus External Orientation: Who Was Right?}

In one sense both the pre-1979 advocates of structuralist internal market orientation and export led growth have been 'proven' correct. SSA's post 1979 economic malaise has been gravely aggravated by the import intensity of national economies and by lack of effective action to maintain production of agricultural and agricultural input/incentive goods. $B u t$, the import strangulation confronting half the SSA economies is in large measure the result of

\footnotetext{
In fact the 'new conventional wisdom' has not been consistent on price intervention (i.e. market management). It has urged major government intervention in respect to grower prices, foreign exchange prices and interest rates in order to raise them and on wage (and less uniformly) salary rates to hold them down nominally and cut them in real terms. It is not, in particular cases, by any means cvident that the advice given (however sensible) bore a close relation to what any actual market process freed from state management would have produced.
}

sluggish export growth which was not balanced by reductions in import dependence, at least in certain key sectors. As a result, high export (more specifically import capacity) growth economies like Botswana and the Cameroon have been better able to weather external shocks, to stabilise and to maintain growth rates of GDP significantly above population.

In another sense both schools seem to have been proven wrong. It has been demonstrated that national (or regional) economic integration requires absolute increases in imports. A halfway house with moderate - but still unsubstitutable - import dependence causes a negative GDP multiplier of up to five to one for import cuts. The case for disregarding exports as a route to strengthening domestic oriented production appears to be fallacious. On the other hand, even for most export oriented economies, it has been impossible to maintain adequate export growth to overcome terms of trade deterioration, weather and other shocks, and to maintain balance. Zambia - an above average if uneven performer in the 1960s and early 1970 s - has since faced ever deepening balance and structural problems with no early resolution in sight, as Philip Daniel's article in this Bulletin shows. Botswana's export led development - very rapid from a very low base - is about to come under severe strain. Unless a major new mine can be developed before 1990; a breakthrough in irrigated agriculture achieved by the same time; or the recent boom in non-traditional exports continues at the same rate (i.e. requiring much larger absolute increases) for the next five years, the 1990 s are likely to be a period of severe strains on balance and low growth (see Charles Harvey's article in this Bulletin).

\section{Has IDS Changed Its Position}

IDS members, apart from being very far from monolithic, have tended to be in the middle (and under fire from several sides) on many of these issues (see, for example, Sender and Smith 1983). Many of the emphases in IDS work on SSA have changed, partly because most members tend to concentrate on issues and areas of analysis they feel have been understressed, and on operational and policy issues they believe are in danger of being overlooked or misinterpreted. Given the changes in SSA, within individual SSA states, in the world economy and in the nature of the analytical dialogue and policy debate on SSA since 1979, it would be surprising if this were not the case. Thus how much of the change is related to perception of altered reality, how much to additional data and how much to altered basic views or interpretations is unclear. Doubtless each is significant and varies between members.

Three themes have, however, remained central in IDS work on SSA. The first is complexity: the danger that 
highly simplified analysis and policy will be both incomplete and inappropriate - a theme running through several articles in this Bulletin, notably those by Caroline Allison, Christopher Colclough and Martin Godfrey. The second is diversity: the need to recognise that SSA economic contexts, structures, policies and performance vary sharply from country to country, illustrated in the articles by Philip Daniel, Charles Harvey and Reginald Green. The third is interaction: that different strands of analysis and policy have a different significance when taken together rather than in isolation - one aspect of the articles by Manfred Bienefeld, Michael Lipton and Hans Singer.

The present Bulletin is part of a continuing process of exploration, rethinking and reformulation. ${ }^{2}$ Its key objective is to contribute to the pressing task of getting some facts straight as a precondition for applied analysis in complex contexts.

The first three articles in this issue centre on some of the underlying factors and urgent concerns in respect to agriculture and food production. Hans Singer's article conveys growing concern about the way in which emergencies have been handled, and explores some practical ways both to improve responses and avert future crises. Michael Lipton seeks to explain the paradox which surrounds high levels of expenditure on agricultural research and notoriously slow growth in agricultural production. Caroline Allison focuses on three major issues of crucial significance to women in their roles as major food producers which have tended towards ambiguity in analyses of rural political economy.

The remaining contributions to this Bulletin look at two questions from various perspectives. First, the need to reassess elements of the old and new 'conventional wisdom' in the light of contemporary developments. Second, the ways in which stabilisation has, or has not, been achieved in specific contexts and how it might be approached more generally.

Christopher Colclough questions the effectiveness of price reform in eliciting desired changes in production and distribution in the light of recent debates. He focuses in particular on the issues of domestic taxation, nominal exchange rates and inflation, pointing to the lack of evidence upon which analysis has been built within what are held to be competing paradigms.

Martin Godfrey reassesses the debate surrounding three of the Accelerated Development Report's policy

\footnotetext{
${ }^{2}$ Three of the articles in this issue are revisions of longer papers prepared for the "Conference on Rehabilitation and Recov'ery in sub-Saharan Africa' held in Paris August 1984, co-sponsored by OECD Development Centre, IDS and CERDI.
}

prescriptions in the context of recent challenges to these. He finds the universal recommendation to increase agricultural exports guilty of the 'fallacy of composition', and postulates food self-sufficiency as the safest basis for food security. He concludes that dogmatic views about devaluation are unwarranted on the basis of country-specific experience in SSA.

One of the two country case-studies, by Charles Harvey, looks at Botswana's national adjustment strategy adopted on government initiative to meet growing balance of payments difficulties. Despite the success of this strategy and its similarity in form to the conventional IMF adjustment package, he stresses that the causes of imbalance in Botswana and the context in which adjustment was undertaken are such as to preclude this case being used as a blueprint of action for the region. The second article, by Philip Daniel, analyses Zambia's inability to withstand economic shocks despite enduring attempts at stabilisation, and concludes that the reasons for this are less straightforward than often believed.

The starting point of Reginald Green's article is the diversity of result revealed by Botswana, Zambia and Zimbabwe in their stabilisation efforts. This questions the use and appropriateness of IMF resources in economies where recovery of import capacity from exports is dubious on technical grounds. He emphasises timing, phasing, sequencing and selectivity if the goal of stabilisation with adjustment is to be achieved.

The last article, by Manfred Bienefeld, suggests that the 'new consensus' on industrialisation is simply the 'old approach' dressed in new rhetoric, and reasserts the need for the former to incorporate some of the basic tenets laid down by the dependency school, broadly defined, whose somewhat bleak prognosis has been validated. He argues that this is necessary not only to understand the 'failure' of industrialisation, but to learn from it and challenge negative developments in the future.

\section{Toward a Consensus of Analysis?}

There is reason to believe that the dialogue on SSA is becoming less heated, rigid and controversial and more exploratory, synthesis building and orientated to African results, at least among some analysts. In terms of clusters of priority actions (if not equally among their relative weights and sequential logic) there is relatively broad agreement among analysts who have historically been viewed as adherents of very divergent paradigms and strategies, although major areas of disagreement persist.

As suggested above, many of the themes of the "new conventional wisdom' clearly needed to be incor- 
porated into both the analytically dominant (if marginal in most policy determining circles) structuralist approaches and operationally dominant (if analytically little supported) modernisation approach. Similarly many of the concerns of the main body of structuralist analysis have proven to be logical missing links in the 'new conventional wisdom', especially at the level of operational use. It is not much use querying who has moved further - most analysts tend to overestimate how much others have shifted towards them and to underestimate their own shifts.

However, this emergence of semi-consensus - or at any rate reasonably polite, mutually intelligible discourse - should not be allowed to obscure four points:

First, agreement is much greater in respect to the short than the long run and to rehabilitation and recovery than to development. Differences of emphasis in the short run often widen into basic differences of analysis, judgement or value system.

Second, if there is an agreement on detailed applied analysis it is that simple, universal answers at the operational level are frequently not available, that all of us know less (as well as more) about SSA than we thought we did five or ten years ago.

Third, in many sectors and contexts the basic data for serious and accurate analysis do not exist, so that articulation between broadly postulated principles and specific cases is very hard, and gives rise to surprising results.

Fourth, increasing consensus at the analytical level is not equally as evident at the policy level, either in SSA or globally.

\section{And of Policy-Makers?}

That policies have changed in and with respect to SSA is self evident. Given the falls in real command over resources within SSA, the collapse of credit ratings for almost all SSA states and the radically more market oriented and resource cutting climate of global economic policy, this is inevitable.

Some changes are fairly standard among both external sources of finance and SSA governments. First, a growing sense of horror and - less uniformly - of weariness at apparently falling back no matter how fast one runs. Second, a deepening realisation that recovery will neither be the automatic result of global recovery nor quick. Third, very heavy emphasis on nominal prices (in effect if not always in intent) and on exports, again less uniformly, especially in acute food crises and among some bilateral agencies. Fourth, a fairly clear (if sometimes suppressed) concern that a satisfactory strategy for the medium and long term cannot be discerned. Fifth, a greater emphasis on efficiency (often not very clearly defined as efficiency for what or for whom), partly because of a belief that adequate resources will not, in fact, be available. Sixth, a great deal of certainty about bits and pieces of policies and programmes - a certainty which is not always very convincingly linked to the quality or consistency of past advice/decisions, to available data or to coherent analysis. Seventh, a growing (and unwelcome) realisation that further demand cuts (bar those resulting from greater output for lower input) are in many cases likely to prove counterproductive in relation to exports and future consumption.

These common elements do not, however, add up to consensus, nor in many cases to policies which are consistent with each other, with the so-called emergent analytical consensus or with any very high probability of success. Most bilateral and international aid/ development agencies as of 1985 appear, at the operational level, to be lagging behind the analytical dialogue (including in some cases their own analysts'), adopting elements of the 1981 'new conventional wisdom' that have not worn well and rejecting elements of their own past programmes which are now being more positively reassessed.

Among SSA governments there is substantial divergence. Most are in practice engaged in crisis containment and damage limitation because they lack the resources or the articulated strategic base to do anything else. A few (e.g. Ivory Coast) still operate on the assumption that cyclical recovery is around the next corner, and another handful (e.g. Nigeria) on draconic cutbacks. In strong economies with firm export bases this may work. Only a minority have either avoided or surmounted crisis (e.g. Cameroon, Botswana) and even these are rather cautious or perplexed as to their medium term prospects. The number with functioning stabilisation/structural adjustment programmes that are likely to survive is arguable. That Ghana and Uganda (and - until recently - the Sudan) are often cited indicates how problematic this category is.

Bilateral and international development agencies are, surprisingly, given the effects of much past advice which has been acted on, very confident both at micro and at broad policy level that they know what Africa should do. Certainly much of their advice is new (though not by any means all - primary export expansion is a theme that dates back at least 65 years) or represents a significant shift in emphasis. The confident assumption that it is all correct, contextually relevant, practically operational and better for having little African involvement, is not new. In many 
respects it is as contrary to the advice of some 'new conventional wisdom' analysts - and indeed some agency analysts - as it is to that of many structuralist or basic needs analysts. Moreover, the agencies are to date unable to provide the resources which their own projections suggest are necessary for people to live, for economies to hold together, and for states to survive until new policies and allocations can bear fruit in production. This, in practice, forces down time and resource horizons and leads back to damage containment more of ten than to structural adjustment, however defined. ${ }^{3}$

\section{Some Conundrums for Analysts and Practitioners}

With analytical dialogue less antagonistic and operational exploration showing the problems that data gaps pose to the implementation of new approaches, opportunity exists for identifying and acting on key areas of data collection and interpretation. ${ }^{4} \mathrm{~A}$ series of conundrums exists.

First, many correlations are weak, go in the wrong direction or are somewhat less than clear in causal direction. For example, correlations over time between actual consumer and official grower prices are rather low. So too are those between grower price movements and overall agricultural output trends. Similarly the correlation between rates of increase in actual consumer (and probable effective grower ${ }^{5}$ ) food prices and rate of growth of food production appears to be negative. ${ }^{6}$ While overvalued exchange rates clearly do contribute to external imbalance, the initial direction of causation in several cases appears to be

\footnotetext{
${ }_{3}$ Alternatively it might lead to concentrating on a selected minority of states - selected for reasons such as tractability. past economic performance, recent policy changes and/or political durability. These might then receive adequate resources. Certainly a look at World Bank fund availabilities and its estimates of inputs needed for structural adjustment programmes suggest it would be hard put to support SAPs in more than a quarter of SSA member states even if it were totally satisf:ed with their proposals. Apart from human considerations. such neo-triage as a policy would increase disagreement among donors (perceptions vary widely among them on the selectability of particular SSA states) and would pose political problems for them at home. Disaster does raise popular demand for increased aid independent of state policy and performance levels.

4 The Paris Conference agreed on over 20 priority clusters which will be presented in the forthcoming volume: Crisis and Recovery in sub-Saharan Africa: Realities and Complexities, (OECD, Paris).

s Low grower food (as opposed to export crop) prices tend to change the marketing channels used more than output. In few African countries does even 50 per cent of commercially marketed food pass through official or even large scale, recorded private channels. In many it is as low as 10 per cent whether because of the absence of such bodies or their evasion by growers.

- In one sense this is perfectly predictable. However, it does raise serious questions as to the responsiveness of supply to price incentives without complementary measures.
}

increases in external imbalance caused by shock leading to overvaluation, not the reverse. These are examples which urgently demand better checking of fairly fragmentary and weak data, and subsequent attempts at more contextual analysis.

Second, it is increasingly clear that the crisis in agricultural production dates back 25 years, not to 1979 or even 1969. It eroded the ability of most SSA economies to respond to post 1979 shocks and has been exacerbated by that inability to respond. It is, however, a separate malaise which recovery in other sectors and economic balances alone is unlikely to cure. As already noted, rises in food prices faster than the Consumer Price Index (true of almost all of Africa since 1979 and common from 1960 on) have not been enough to reverse this pattern. Clearly more study is needed. In the short run more food aid is vital, but preferably within a context in which (unlike the record in the Sahel) it lays a foundation for averting, not increasing future food aid needs - themes discussed in Hans Singer's article. Another strand is serious examination of what the African farmer does, knows, wants and could and would do in different contexts. Women have received little attention, although it is their actions - or inactions - which largely determine whether food production strategies and policies succeed or fail - an area explored here by Caroline Allison. In addition, the previously unfashionable view that knowledge on how to raise output in safe, tested ways which can be used by peasant farmers, was very scarce in Africa so that research (and improvement in its cost effectiveness) was critical to agricultural analysis, and policy has been gaining support. This is exemplified by Michael Lipton's article in this collection.

These by no means exhaust the data gaps and interpretational conundrums as illustrated in this Bulletin by the triad of articles on the requirements of and interrelationships among stabilisation and structural adjustment under different conditions. But given the present quasi consensus and ongoing dialogue anong analysts, they do illustrate the need to build a firmer data base, including more sectoral and comparative work. Straight facts are a precondition for straight applied analysis - especially in complex contexts. Their paucity in SSA calls for structural adjustment almost as much as does the paucity of exports and is, perhaps, one in which analysts have a greater direct comparative advantage in production.

\section{Economic Malaise: Human Tragedy}

It is all too easy in analysis, dialogue and prescription to abstract from what the economic malaise in subSaharan Africa means to the population of the region. In that respect the grim panorama of famine flashing 
across television screens since the second half of 1984 may be as important to analysts, advisers and technocrats, who are at one level well acquainted with the realities of SSA, as to ordinary viewers and decision-takers who had previously paid them little attention.

The root causes of this human tragedy are general economic - and especially agricultural - failure, exacerbated by the politics of food. Of the 30 million at risk of starvation in 1984-85 probably at least one million women, infants, men and children died between 1984 and 1985 who would not have done so had adequate domestic food production, adequate export earnings to finance food imports or adequate food aid been available.

Starvation is only the most evident cause of death directly resulting from economic malaise. Others include: national child immunisation and vaccination programmes cut by import strangulation in respect to vaccines and fuel; inadequate supplies of safe drinking water; and the spread of contagious, poverty related diseases.
Death is only the last stage of immiserisation. Declines of 50 per cent or more in real consuming power of salaries, of minimum wages, of informal sector urban incomes, of purchasing power of export crops and of basic output of food to eat in 'moderately' drought impacted areas cannot easily be brushed aside.

The human costs of breakdowns in once reasonably well functioning basic health, education and water services are equally appalling. Ask the woman who has to walk 12 miles a day because the village pump cannot be used as a result of import constraints on fuel, spares or the mobility of the repair technician.

Perhaps even more dangerous - not least from the point of view of future production responses to any policies and incentives - is a growing sense of hopelessness. Six to 25 years of economic failure or damage limitation and loss of what once had been attained, immiserises morally and spiritually as well as materially. For IDS members, the erosion of hope, morale and self-confidence among their SSA friends has been one of the most painful signs of the continued evolution of economic malaise.

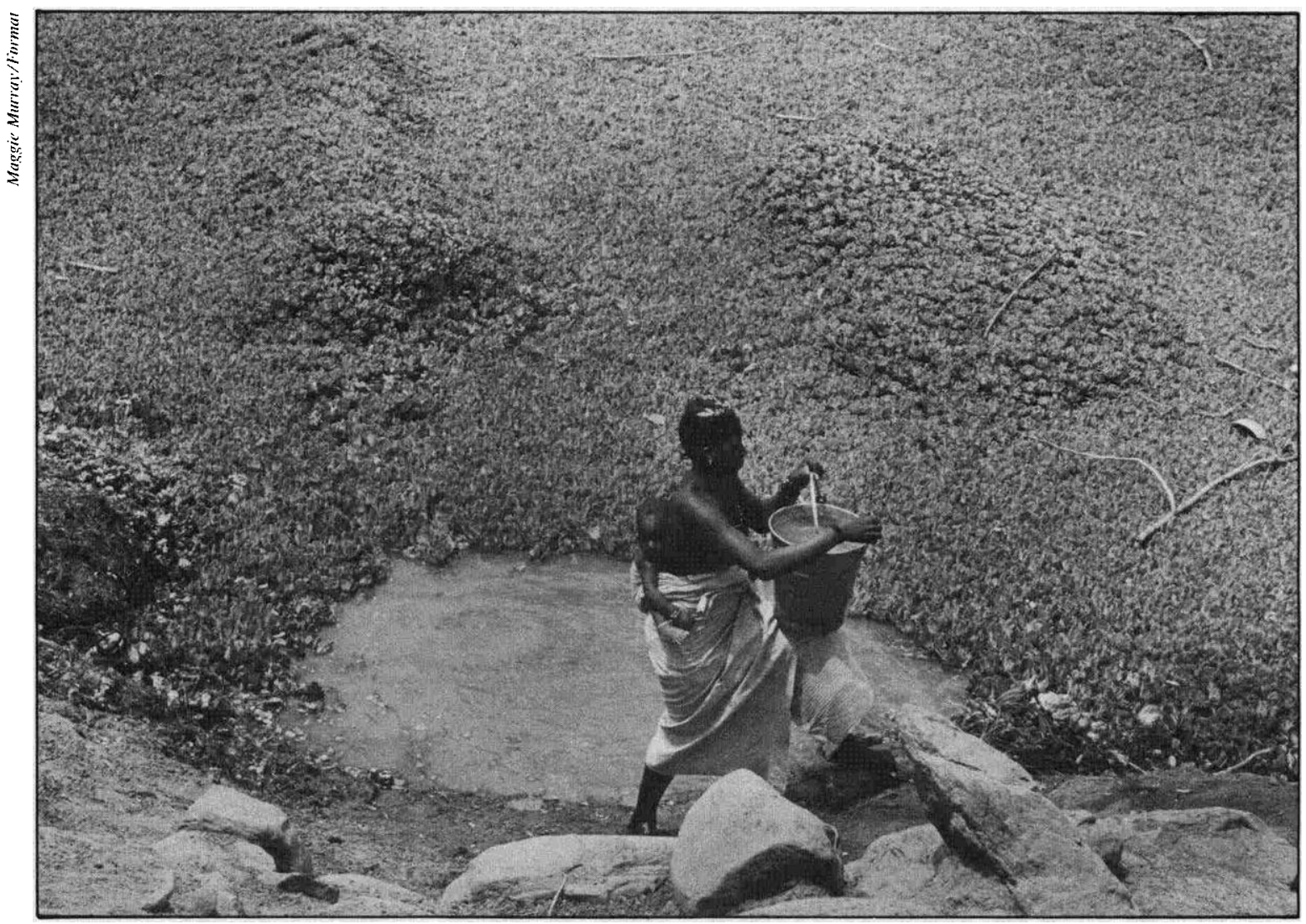

Many traditional water sources should not be used for human consumption. 
It is false to see the human dimension as in conflict with analytical or policy aspects. True production oriented policies that pay no attention to shielding poor and vulnerable groups are in real danger of producing repeated and wide-scale disaster in countries as poor as many in SSA. But it is precisely because so many Africans and so many African economies are poor that production is a vital goal. With so few resources available, inefficiency in using them to achieve priority targets has very serious consequences.

For the concerned analyst of SSA today a prime responsibility is to get more facts straight. Knowing what has and is happening, and why, is basic to doing something about it. Trial and error is, at least in SSA today, an expensive way forward, not just in terms of production but in terms of human lives.

\section{References}

Allison, C. and R. Green (eds), 1983, 'Accelerated Development in sub-Saharan Africa: What Agendas for Action?" IDS Bulletin, vol 14 no 1
Carlsson, J. (ed), 1983, Recession in Africa, SlAS, Uppsala

Clay, E. and E. Everitt (eds), 1985, 'Food Aid and Emergencies', Discussion Paper 206, 1DS, Sussex

Green, R. (ed), 1985, 'Sub-Saharan Africa: towards oblivion or reconstruction?', Journal of Development Planning, No 15, United Nations, New York

Green, R. and H. W. Singer, 1984, 'Sub-Saharan Africa in Depression: The lmpact on the Welfare of Children', World Development, March

OECD, forthcoming. Crisis and Recovery in sub-Saharan Africa: Realities and Complexities, Paris

Sender, J. and S. Smith, 1984, "What's Right with the Berg Report and What's Left of 1ts Critics?", Discussion Paper 192, 1DS, Sussex

World Bank, 1981, Accelerated Development in sub-Saharan Africa: an Agenda for Action, Washington DC

-1984, Tovards Sustained Development in sub-Saharan Africa: a Joint Programme of Action, Washington DC 